\title{
POLÍTICA SOCIAL, GESTÃO E NEGÓCIO NA PRODUÇ̃̃O DAS CIDADES: o programa Minha Casa Minha Vida "entidades"
}

\author{
Cibele Saliba Rizek* \\ Caio Santo Amore * * \\ Camila Moreno de Camargo **
}

\begin{abstract}
Este texto apresenta resultados de pesquisa sobre o Programa Minha Casa Minha Vida - Entidades, uma das modalidades da política de habitação inaugurada em 2009, no âmbito da sua apreensão como parte da constelação de programas sociais dos governos Lula e Dilma Roussef. Esses resultados de pesquisa ainda em curso apontam para dilemas, paradoxos e dimensões que envolvem a demanda, os operadores, os processos de produção dos conjuntos habitacionais e a produção e reprodução das formas de desigualdade e segregação socioespacial na cidade de São Paulo, assim como a constituição de um campo de consensos que permeia as relações entre movimentos de moradia e Estado, no interior do que se pode denominar de "lulismo".

Palavras-chave: Política de habitação. Movimentos de moradia. Políticas sociais. Periferias.
\end{abstract}

\section{APRESENTAÇÃO}

Este texto apresenta resultados de uma pesquisa em processo de finalização, realizada nos últimos dois anos e busca explicitar reflexões que permearam (e ainda estão no horizonte inconcluso da investigação) a coleta de dados e de depoimentos: as incursões etnográficas ainda não inteiramente concluídas; e as sistematizações e análises de dados quantitativos secundários fornecidos pela Caixa Econômica Federal ou por outras fontes oficiais. A pesquisa é o resultado de um projeto submetido e aprovado em edital do Ministério das Cidades e do CNPq, e tem envolvido pesqui-

* Doutora em Sociologia. Professora do Programa de Pós Graduação em Arquitetura e Urbanismo do IAU/Universidade de São Paulo. Pesquisadora do Centro de Estudo dos Direitos da Cidadania, também da Universidade de São Paulo.

Av. Trabalhador São-Carlense, 400. Centro. Cep: 13566590. São Carlos - São Paulo - Brasil. cibelesr@uol.com.br

** Doutor em Planejamento Urbano. Professor do Depto de Tecnologia da Arquitetura e do Urbanismo da FAUUSP.

Peabiru Trabalhos Comunitários e Ambientais. Rua Vitorino Carmilo, 453, casa 7. Barra Funda. Cep: 01153000 - São Paulo - São Paulo - Brasil. caiosantoamore@gmail.com

${ }^{* * *}$ Arquiteta Urbanista. Doutoranda do Programa de PósGraduação do Instituto de Arquitetura e Urbanismo, Universidade de São Paulo

Avenida Trabalhador Sancarlense, 400. Cep: 13500-210. São

Carlos - São Paulo - Brasil. cmcamargo.urb@gmail.com sadores ligados ao IAU/CENEDIC (Instituto de Arquitetura e Urbanismo da Universidade de São Paulo, campus São Carlos, e Centro de Estudos dos Direitos da Cidadania, FFLCH-USP) e à assessoria técnica Peabiru. O projeto e a pesquisa em curso tem como objeto a produção realizada (ou ainda a se realizar) pelo Programa Minha Casa Minha Vida - Entidades no estado de São Paulo, embora a sistematização de informações secundárias, necessária para o dimensionamento e a reflexão sobre o programa, tenha se estendido ao âmbito nacional. ${ }^{1}$

O Programa Minha Casa Minha Vida (PMCMV) tem sido apresentado como uma das grandes realizações dos governos Lula e Dilma e vem marcando as cidades brasileiras de forma indelével. No âmbito desse programa, foram contratadas 3,4 milhões e entregues 1,7 milhões de unidades habitacionais, incluindo todas as faixas de renda e todas as modalidades

${ }^{1}$ Além dos autores, a equipe de pesquisa é constituída por Andrea Quintanilha de Castro (mestranda pelo IAU-USP/ SC e arquiteta/urbanista da Peabiru), Rafael (mestrando pela FAU-USP e arquiteto/urbanista da Peabiru), Daniela Perre Rodrigues (arquiteta/urbanista da Peabiru), Marina Barrio Pereira (arquiteta/urbanista da Peabiru), além dos estudantes de graduação Ana Teresa Carvalho (FAU-USP), Caio Jacyntho e Giovanni Bussaglia (IAU-USP/SC), que participaram em períodos diversos. 
de produção. Este texto tem como objeto a modalidade "Entidades", que compõe a chamada faixa 1 do programa (atendendo a famílias com até 1.600 reais de renda mensal). A produção dessa modalidade é contratada por organizações populares, associações, cooperativas, que compõem o universo de "entidades", que devem se responsabilizar integralmente pela indicação das famílias e por todo o processo de produção - da pesquisa do terreno à entrega das chaves, passando pelo desenvolvimento e aprovações de projeto e execução das obras civis. Trata-se, de um lado, de uma produção ínfima em termos quantitativos, se comparada a toda produção do programa; de outro lado, a presença e permanência (para não dizer insistência) dessa modalidade tem uma dimensão política paradigmática, apoiando-se na tradição de políticas habitacionais autogestionárias, envolvendo os mais representativos movimentos de luta por moradia e reforma urbana do país. Considerar, assim, o Programa Minha Casa Minha Vida e sua modalidade "Entidades" como parte das políticas sociais dos governos Lula e Dilma, e como elemento da constelação de políticas sociais e urbanas que compõem o novo diagrama de relações entre Estado e pobreza, entre Estado e classes populares, é uma das especificidades de nossa abordagem. ${ }^{2}$

A partir de um primeiro momento exploratório de pesquisa - necessário à apreensão do conjunto dos empreendimentos contratados, em obras ou concluídos -, foram selecionados dois empreendimentos em função de uma série de características e especificidades do local onde estão (ou serão) implantados, dos aspectos urbanísticos, arquitetônicos e

${ }^{2}$ Essa abordagem vem sendo desenvolvida em um conjunto de projetos de pesquisa, seminários, interlocuções em especial no âmbito dos projetos "A nova gestão da questão social no Brasil: entre participação e mercantilização", CNPq-IRD, 2011-2015; "Offre institutionnelle et logiques d'acteurs : femmes assistées dans six métropoles d'Amérique latine”, LATINASSIST - ANR Les Suds II, 2011-2014. Além dessas dimensões, a experiência de pesquisa e de intervenção de Caio Santamore de Carvalho no âmbito da

Peabiru, bem como a pesquisa de Camila M. de Camargo foram imprescindíveis para a apreensão da problematiza-

ção de algumas das dimensões desses resultados. Destaquem-se, ainda, as análises e diálogos da Rede de Pesquisa sobre Inserção Urbana dos projetos escolhidos pelo Ministério das cidades e CNPq. produtivos dos conjuntos, da composição ou criação da "demanda", de públicos-alvo ou beneficiários das unidades habitacionais, e das origens e formas de organização das entidades, suas tramas e tessituras associativas.

Dessa perspectiva, para além dos elementos urbanos propriamente ditos que permeiam a produção do PMCMV e de sua modalidade "Entidades", a análise dos processos em curso dessa pesquisa procura alimentar e se inserir nas reflexões mais amplas sobre programas e políticas sociais, uma vez que o programa MCMV, particularmente em sua modalidade "Entidades", ajuda a desvendar o lugar (em sentido metafórico e literal) das políticas urbanas e sociais no Brasil dos anos 2000, observando dimensões relativas à inserção e às (novas e velhas) formas de segregação urbana, reproduzidas ou aprofundadas pelo ciclo de produção de moradias periféricas nas bordas da Região Metropolitana de São Paulo. Procura, ainda, refletir a respeito dos "protagonismos", práticas, universos de tensão entre as dimensões politizantes e profundamente despolitizantes que podem ser vistas como um dos destinos das associações e entidades, resultantes ou não dos longos processos de luta pela moradia e pela cidade no Brasil. Trabalhos de Sísifo ou conquistas, na medida das urgências, as políticas de moradia pensadas como políticas sociais permitem que se possam vislumbrar desdobramentos e dimensões que cruzam a produção do espaço urbano, da moradia e do quadro de pactos e inflexões do chamado "lulismo" como forma de arranjo político que caracteriza as relações de força no Brasil contemporâneo. ${ }^{3}$

\section{POLÍTICA DE HABITAÇÃO E POLÍTI- CA SOCIAL: urgência e gestão \\ Da perspectiva do momento em que se desenha o Programa Minha Casa Minha Vida \\ ${ }^{3}$ Singer, A. et al. Capitalismo e modernização periférica no Brasil do Século XXI: desigual e combinado - 2013 CENE-} DIC, FFLCH. Mimeo. 
e sua modalidade "Entidades", em 2009, é preciso ter como referência o fato de que um conjunto nada desprezível de processos e injunções tinha levado o Brasil a se configurar como a sexta economia capitalista do mundo, combinando crescimento econômico e suas oscilações, com a reprodução de desigualdades, ${ }^{4}$ o que parece - ao que indicam alguns autores - diminuir relativamente menos do que a pobreza e a miséria. Foram tempos marcados por uma relativa estabilidade do mercado de trabalho, apesar da desaceleração dos anos recentes (Leite, 2011), pela criação de empregos formais, embora caracterizados por baixos salários e postos de trabalho precarizados. O momento aponta, assim, duplicidades, disjunções e processos de conformação complexa, que parecem se relacionar a uma transformação da composição do emprego a partir das redefinições da inserção brasileira nos processos mundializados de financeirização desde os anos noventa. Em conjunto com a ampliação da base do assalariamento, o período também foi marcado pela instituição das políticas sociais redistributivas, como o Bolsa-Família e por um significativo aumento do salário mínimo, desde o início do primeiro Governo Lula. Ao mesmo tempo, com o próprio aumento da massa de empregados, alguns autores indicam um recrudescimento das condições de trabalho, que são notadas pelo número de acidentes e mortes no trabalho, pela rotatividade da força de trabalho e pelo aumento das terceirizações.

A hipótese inicial de pesquisa era a de que seria possível pensar numa dualidade que perpassaria a montagem do quadro de políticas sociais no Brasil, estendendo-se às modalidades do Programa Minha Casa Minha Vida e Minha Casa Minha Vida - Entidades. ${ }^{5}$ Essa

${ }^{4}$ Singer, A. et al., idem.

${ }^{5}$ Hipótese que orientou o projeto de pesquisa mais amplo com o qual dialoga: "Emergência e reinvenção: "novas" e "velhas" políticas sociais no Brasil", projeto de pesquisa Universidade de São Paulo (USP-FFLCH-Cenedic) / IRD no âmbito do convênio de cooperação científica CNPq / IRD (Edital CNPq N $\mathrm{N}^{\circ}$ 17/2013), 2013 - 2016, coordenado por Cibele Saliba Rizek e Isabel Georges. Ver também a esse respeito o Projeto Singer, A. et al. Capitalismo e Modernização periférica no Brasil do Século XXI: desigual e com- mesma dualidade poderia ser percebida num leque mais amplo de programas e proposições: na política de apoio ao agronegócio à qual se soma o incentivo à agricultura familiar; na somatória de incentivos à produtividade do trabalho com intensificação, acidentes e mortes ao mesmo tempo em que se criava uma pequena secretaria de economia solidária; ou mesmo na combinação entre expansão do ensino público universitário com um programa de repasse de verbas ao ensino superior privado por meio do PROUNI, entre outros exemplos. Do nosso ponto de vista, por hipótese, essa mesma dualidade ocorreria com o programa Minha Casa Minha Vida. De um lado, a produção habitacional se situa em escala, altamente subsidiada e voltada para as famílias de mais baixa renda (numa proporção que talvez nem os mais otimistas do campo da reforma urbana imaginariam), como forma de incentivo econômico à cadeia produtiva da construção civil e a outros ramos industriais (da fabricação de insumos à indústria de mobiliário, eletrodomésticos e linha branca), com importantes desdobramentos relativos aos vínculos entre capital financeiro e capital imobiliário (grandes construtoras à frente), à alta generalizada de preços de imóveis e aluguéis, à produção de novas periferias e ao aprofundamento da segregação socioterritorial. De outro lado, há a modalidade "Entidades", que poderia conferir alguma possibilidade de produção habitacional, dentro do quadro de lutas e conquistas dos movimentos sociais por moradia. Entretanto, dentro dessa complexa engrenagem, o Programa MCMV na modalidade "Entidades", de acordo com dados oficiais coletados na pesquisa (e a despeito de uma baixa confiabilidade desses dados), apesar da meta de compor 3\% de toda a produção do programa em âmbito nacional, até o final de 2013, tinha contratado menos de 1\% de todas as unidades habitacionais do Programa. Seria, então, possível, indicar um vínculo complexo, com transformações nada desprezíveis, en-

binado - 2013 CENEDIC, FFLCH, cuja investigação está em curso e cujo término está previsto para 2015. 
tre o amplo apoio dos movimentos de luta por moradia e reforma urbana e as transformações efetuadas no âmbito da política urbana e habitacional do governo, incluindo a formulação da versão "Entidades". Tal vínculo teria consequências importantes para um rearranjo do campo de forças nas relações e tensões entre essas partes, para a operação de um novo diagrama de relações entre produção de moradia e luta pela apropriação da cidade (ou seu avesso, mais uma vez, na disjunção entre moradia e cidade, que perpassa a produção pública de moradias desde o $\mathrm{BNH}$ ), assim como para os limites porosos entre as práticas de entidades e movimentos ligados ao programa, o mercado imobiliário e a construção de mercadorias políticas. ${ }^{6}$

Esses processos poderiam apontar talvez menos para uma dualidade do que para modulações importantes, com fortes consequências políticas no sentido da construção de um campo de consenso fora do qual seria difícil ou quase impossível a produção de moradia para as camadas mais pobres da população, a partir de uma perspectiva de afirmação ou de consolidação dos movimentos vinculados à luta pela habitação popular. Nesse caso, talvez se possa afirmar menos dualidade do que modulações, com consequências importantes para um rearranjo das relações de força e poder entre o Estado e os movimentos sociais, devidamente transformados em operadores do programa.

Assim, no âmbito mais geral das polí ticas sociais brasileiras, esses processos permitiriam identificar menos dualidades que modulações, mutações e deslizamentos resultantes de um processo econômico que combii na crescimento com importantes déficits de $\therefore$ direitos sociais, remediados de modo bastante ลे focalizado e pontual, na medida das urgências $>$ mais flagrantes, entre as quais, a moradia. Esses déficits e as carências de resolução mais

${ }^{6}$ Quanto a essa noção, ver MISSE, Michel. "Rio como um bazar, a conversão da ilegalidade em mercadoria política". Rio de Janeiro: Insight Inteligência, v. 3, n. 5, 2002, p. 12-16. Disponível em: http://www.necvu.ifcs.ufrj.br/images/2oriocomoumbazar.pdf. Consultado em 23 de agosto de 2013. urgente $^{7}$ foram sendo construídos ao longo da história brasileira em um processo de contínua atualização, sem que se alterassem os marcos e as formas mais agudas de desigualdade, sobretudo no que se refere às relações de classe. ${ }^{8}$ Na verdade, é possível ainda apontar para um conjunto de modulações, atualizações e combinações que desenham formas de consenso e acabam por se constituir quase como "modo de regulação" de conflitos dentro de um quadro de formas de dominação redesenhadas. ${ }^{9}$ talvez como rearranjo e atualização dos "jeitões e jeitinhos" transformados em regra não escrita das relações micro e macrossociais.

É nesse conjunto de questões sobre a sociabilidade política brasileira, suas conformações e seus deslizamentos, que se inserem a reflexão e a pesquisa a respeito das políticas sociais recentes. Como pensar a constelação Bolsa-família, PRONAF, PROUNI, Minha Casa Minha Vida? São saídas para a extrema pobreza, ou formas de diminuição da desigualdade histórica brasileira? Constituem a gestão da pobreza e de suas urgências? Constroem portas de saída para as desigualdades? As respostas devem ser contempladas a partir de um programa complexo de pesquisa e reflexão. Tal programa se situa no cruzamento dos diversos projetos em andamento já mencionados, em-

${ }^{7}$ A questão do déficit de moradia não é simples nem pode ser naturalizada. Como se sabe, há uma importante discussão a esse respeito entre arquitetos, urbanistas e cientistas sociais brasileiros. Basta lembrar que o número de imóveis desocupados se equipara a um suposto déficit, cuja composição se ancora fortemente na carência de habitações para a faixa de renda de 0 a 3 salários mínimos. As discussões e seminários das equipes de pesquisa sobre o PMCMV no âmbito dos projetos CNPq e Ministério das Cidades têm apontado essa diferença de modo bastante claro.

${ }^{8}$ Como afirmou em texto clássico Oliveira ([1972] 2003), o avanç capitalista no país foi feito sob a égide do atraso, o que parece, à primeira vista, um paradoxo, mesmo que seja necessário redefinir, a cada momento da história econômica e sociopolítica do país, o que se entende por atraso e por modernização.

${ }^{9}$ Francisco de Oliveira. "Jeitinho e jeitão", Piauí, outubro de 2012. Oliveira ainda aponta que, dentro dessa matriz da sociabilidade do jeitinho, da proximidade e cordialidade, ou dos antagonismos em equilíbrio, ou do horror às distâncias, está a falta de uma solução para a questão do estatuto social do trabalho. Ele se configura em uma das maiores marcas do moderno atraso brasileiro, combinado e talvez pouco superado pelas formas de nossa modernização, constituindo um complexo de características que poderiam definir um ethos transversal às relações sociais. 
bora seja fundamental perceber que, do ponto de vista cultural e político, o alívio das carências enseja situações bastante diversas, indica perspectivas de conquista de direitos voltados à redução das desigualdades sociais, e expressa melhoria das condições de vida privada, sem necessariamente sinalizar para um maior envolvimento com as questões públicas e políticas. Por meio dessas incursões no campo das políticas sociais, tem sido possível identificar um novo diagrama de relações, em que se ancoram permanências e redefinições de um campo de forças e de tensões entre sociabilidades e suas formas de expressão, quer no âmbito da politização, quer no âmbito da despolitização das relações entre pobreza e cidade. ${ }^{10}$

Um amplo conjunto de dimensões socioculturais e político-ideológicas relevantes se impõe como possibilidade de pesquisa e investigação, especialmente em regiões periféricas das grandes cidades, onde populações de baixa renda ou submetidas a vulnerabilidades de toda ordem estão em interação com uma diversidade de novos agentes nos últimos 15 a 20 anos. Entre tais agentes, incluem-se: ONGs, OSs, Fundações e associações e entidades de diversas origens (desde aquelas vinculadas a movimentos sociais até aquelas de origem empresarial, passando por entidades confessionais), coletivos culturais, funcionários públicos de diversas instâncias e grupos político-partidários, estabelecendo-se relações que remetem a práticas de assistência social, cultura, qualificação profissional, melhorias urbanas, regularização e acesso à moradia, entre outras. Esse novo contexto vem implicando reconfigurações nos modos de pensar, viver e compreender as desigualdades e a pobreza, as perspectivas de melhora ou alívio das situações de urgência que as afligem: vão de uma melhor inserção no mercado de trabalho - por

${ }^{10}$ Em algumas das reuniões dos grupos formados pelas entidades em consórcio, encontramos os mais pobres entre os pobres em situações muito evidentes de nomadismo urbano involuntário, marcado não raro por situações de violência de gênero, por expulsões, remoções ou mesmo violências domésticas, cujos relatos permitem pensar em situações que autores como Agamben caracterizariam como "vida nua". meio de "capacitações" das mais diversas, ou por meio de incursões no universo dos empreendedorismos no âmbito econômico, social ou cultural - até a demanda por direitos da cidadania, passando por uma suposta integração à cidade por meio da propriedade (ou da promessa da) da habitação, assim como por formas de inserção "social" por meio de cursos e atividades. Assim, o rendimento obtido pelo Programa Bolsa-Família e o acesso à casa própria por meio do Programa Minha Casa Minha Vida, entre as demais ações de integração dos pobres citadas anteriormente, poderiam se configurar como direitos, seriam novas figurações, conformariam sujeitos de direitos? Esses direitos descortinariam novas linguagens do que seja direito e novas reivindicações por direitos, ao propiciar expectativas de redução das enormes desigualdades sociais? Ou estaríamos diante de outras questões, de cunho econômico - especialmente em relação ao aquecimento do mercado imobiliário, com lançamentos relativos ao segmento econômico, e (ou) aquecimento da economia a partir da incorporação pelo consumo e pelo crédito? Ou ainda, de uma combinação aparentemente insólita e nebulosa entre políticas anticíclicas de cunho econômico e a constituição de clientelas de novo tipo, dimensões que se dissolvem umas nas outras? ${ }^{11}$ Seria possível flagrar, por meio da análise do Programa Minha Casa Minha Vida "Entidades", outro diagrama de leitura e de inteligibilidade das muitas relações entre movimentos, associações, Estado, formas de operação e populações-alvo, cujas narrativas, descrições e análises estejam ancoradas em novas formas de nomeação e categorização, que combinam as velhas e as novas precariedades e formas de pobreza, bem como velhos

${ }^{11}$ Essa dimensão tem como pano de fundo as questões colocadas pela hipótese da hegemonia às avessas (Bello, 2012 e Oliveira, 2007, Oliveira, Braga e Rizek, 2010), na medida em que ela sugere que a perspectiva dos direitos teria sido muito enfraquecida por processos que estariam contribuindo para a naturalização da desigualdade reproduzida pelo mercado. Nesse contexto, o aumento da integração social e os ganhos salariais das categorias mais mobilizadas não estariam propiciando uma significativa politização acerca daquelas questões, tendendo a manter os seus interesses circunscritos ao plano da estrita necessidade. 
e novos modos de enquadrá-las, geri-las, acomodá-las na dobra entre programas e políticas sociais, no encolhimento e enquadramento da ação de movimentos, associações e lideranças no avesso da constituição de sujeitos políticos dotados de um horizonte de autonomia?

Entretanto, cabe mencionar, com Sanfelici (2013), que "o empenho de especialistas e arautos desse novo modelo de crédito imobiliário em apresentá-lo como uma solução para o equacionamento do déficit habitacional no Brasil". Essa necessidade de justificar o modelo liberalizante através de metas sociais para cuja solução ele visivelmente não está apto leva algumas publicações a ambiguidades notáveis. A publicação da FGV "Projetos sobre crédito imobiliário", por exemplo, reconhece a concentração do déficit habitacional brasileiro nos estratos de renda de até 5 salários mínimos e admite a necessidade de subsídios para erradicar esse déficit. Porém, após elogios aos modelos de financiamento securitizado implantados em países como Espanha, EUA e Chile, o documento sugere que quase $80 \%$ do déficit no Brasil pode ser eliminado por mecanismos de mercado. Além disso, no que se refere aos subsídios oferecidos para os restantes $20 \%$, o documento recomenda que o país reproduza o modelo chileno de condicionali-

dades para a concessão dos subsídios: "o pre-

ণ tendente ao subsídio deveria comprovar uma Фั่ poupança prévia, algo como $15 \%$ do valor do imóvel financiado [...]" O próprio documento admitira, poucas páginas antes, "que o modelo chileno deixou de fora justamente a população mais pobre que é, por razões óbvias, incapaz i de poupar [...]" (Sanfelici, 2013, p.107).

Como apontam alguns autores, os países da América Latina, tal como se evidencia pela última citação, se apresentam como uma espécie de "laboratório" de uma nova geração de políticas sociais, tidas como intermediárias entre a proteção social e a luta contra a pobreza (Lautier, 2012; Latinassist, 2010; Destremau e Georges, 2014). Essas políticas são o palco da ação de um conjunto de atores - instituições pú- blicas, nos seus respectivos níveis territoriais, organizações internacionais, nacionais e locais, ONGs, empresas, associações e uma grande diversidade de atores privados "intermediários". Torna-se, então, uma "questão de pesquisa" a necessidade de desvendar, em cada faixa de políticas e programas, permanências, continuidades e pontos de inflexão que permitiriam perguntar sobre os critérios de periodização, redefinições, deslizamentos, reconfigurações. ${ }^{12}$

Além da caracterização de pontos de inflexão e de sua magnitude, é possível acompanhar alguns pesquisadores que apontam a importância das relações entre setores e políticas setoriais no que tange ao nível das intermediações de seus agentes entre o Estado e a assim chamada "sociedade civil", isto é, os operadores dessas políticas (Rizek, 2013). Dessa forma, para além de tentar flagrar supostas "lógicas" nacionais ou setoriais, talvez seja necessário buscar os mecanismos que levam tanto à mitigação como à (re) produção das desigualdades sociais no seu âmbito mais visível - a produção do espaço urbano, as grandes cidades.

As situações de carência e desigualdades habitacionais e urbanas se conformam, assim, como um dos índices mais evidentes e visíveis das modulações contemporâneas da questão social brasileira. ${ }^{13}$ Se essa afirmação tem alguma validade, se ela ganha um contorno significativo dessa invenção moderna do social - tão bem flagrada por Hannah Arendt -, é possível apontar que, por meio dela, se desenham alguns dos principais embates sobre a pobreza, sobre suas configurações, para além do traçado

${ }^{12}$ Dessa perspectiva, seria possível indagar as mudanças e permanências entre o Plano Nacional de Habitação herdeiro do Projeto Moradia, elaborado por quadros do Partido dos Trabalhadores e por intelectuais vinculados à questão urbana - e o Programa Minha Casa Minha Vida.

13 Dessa perspectiva cabe salientar alguns eventos no âmbito da cidade de São Paulo que permitem problematizar, por um lado, a diferença entre déficit habitacional e demanda do PMCMV e MCMV- Entidades. Por outro lado, algumas ocupações na zona Sul e Leste da cidade, especialmente aquelas que foram lideradas pelo MTST (Movimento dos trabalhadores sem teto), Nova Palestina e Copa do Povo, parecem apontar algumas dimensões que permitem afirmar que os programas e políticas sociais estão longe de se configurar um equacionamento mais permanente dos desdobramentos da questão social no âmbito da moradia e da cidade. 
e dos caminhos que conduzem para uma reflexão sociológica da adaptação e legitimação das formas de contagem, classificação, cálculo, gestão, governo moral ${ }^{14}$ e controle dos "pobres". No caso dos programas de habitação, como parte de uma complexa cadeia produtiva de importância econômica inegável, são dimensões de dinamização econômica que se sobrepõem à dimensão da moradia como direito, ou sobre a dimensão do direito à vida urbana e à cidade? As políticas recentes de provisão de moradia dizem respeito à moradia como direito e forma de inserção urbana, ou se constituem, principalmente, como desdobramentos da produção de uma habitação social de mercado (Shimbo, 2012) - no caso da pesquisa relatada, supostamente mediada por associações e movimentos de cunho popular? É possível problematizar as dimensões e resultados dos programas de produção de moradia no cruzamento entre formas de integração ao universo da propriedade da casa (dispositivo que merece e precisa ser questionado e tensionado como tal) e ao universo urbano (condição inescapável de mais de $80 \%$ da população brasileira), bem como de reprodução e aprofundamento de importantes desigualdades socioespaciais? ${ }^{15}$

Tendo em conta a política habitacional como parte das políticas sociais, cabe apontar sua centralidade em relação a uma polêmica inconclusa que atravessa a montagem, a narrativa e os projetos que conferiram forma e sentido à questão social e seus paradoxos, bem

${ }^{14}$ Ver, a esse respeito, Gouvernement moral des pauvres et dépolitisation des politiques publiques en Amérique latine in Borgeaud-Garciandía N., Bruno Lautier L., Peñafiel R., Tizziani A. (dir.), Penser le politique en Amérique latine: la recréation des espaces et des formes du politique. Paris, Karthala, p. 19-36.

${ }^{15}$ Ver, a esse respeito, um conjunto de referências como, por exemplo, Ivo, 2008 onde se lê: "Além das questões relativas à abrangência de tais soluções, especialmente nas sociedades periféricas, em que a grandeza quantitativa do 'excedente' (setor informal) torna ainda mais urgente e, ao mesmo tempo, mais complexa a ação do Estado, o confronto dessas colaborações recoloca, no centro do debate, as relações intrínsecas e contraditórias entre a proteção da cidadania e o universo do trabalho e dos trabalhadores. Ou seja, até que ponto a generalização dos 'mínimos', nos programas de renda mínima de cidadania, por exemplo, contribuem para reduzir formas de integração no âmbito da sociedade do trabalho ou contribuem, igualmente para aprofundar as condições das desigualdades sociais?" (Ivo, 2008: p. 107); (Shimbo, 2012); (Rolnik e Nakano, 2009). como seus desdobramentos contemporâneos no Brasil. Das grandes questões às concepções de "pobreza, desigualdades, exclusão e vulnerabilidade social" como formas de nomeação e identificação e, nessa medida, como dimensões políticas, essas "noções impõem normas de percepção do próprio objeto, em seu processo de apropriação, que se inscrevem como realidade, conformando a prática dos sujeitos sociais." Assim, a pesquisa e as estatísticas formuladas por instituições, como o Estado, articulam-se diretamente com o mundo social e constituem um construto que resulta e interfere, constantemente, sobre as práticas de atores e "agentes sociais". Talvez dessa perspectiva, as nomeações e cálculos do déficit de moradias no Brasil seja, de fato, exemplar. Mas "a objetivação das noções e categorias de natureza científica, quando se transformam apenas na agregação de informações, sem referências às condições de produção da história social, acabam por se instituir como técnica dissociada das formas concretas de como se reproduzem dimensões políticas e injunções sociais" (Ivo, 2008: p. 107). Como parecem demonstrar fragilidade e incerteza relativa aos dados sobre a produção de moradia do programa MCMV e, especificamente de sua modalidade "Entidades", é preciso observar um vínculo entre as formas de identificação e assinação da pobreza e as questões históricas que emolduram as relações entre pobreza e industrialização, pobreza e suas expressões urbanas desde a colônia, bem como o binômio que ocupou parte significativa do debate das ciências sociais na segunda metade do século XX: os vínculos contraditórios entre desenvolvimento e pobreza. ${ }^{16}$ Se houve uma assimilação da pobreza às situações informais de trabalho, que receberam nomes diversificados ao longo da história social brasileira, a dissociação entre pobreza e trabalho parece se conformar clara-

${ }^{16}$ Essa discussão, de escopo macrossocial, desenha e redesenha a pobreza como marginalidade, massa marginal, trabalho excedente, exclusão e apartheid social, entre outras designações ao longo do pensamento social brasileiro. Pode se citar, como exemplo, a discussão sobre as categorias subemprego ou subocupação entre os anos de 1970 e 1980. 
mente a partir da reversão das expectativas de integração por meio do trabalho assalariado, por meio do que se poderia identificar como condição salarial. Mais recentemente, a partir dessa reversão, é possível encontrar exemplos de formalização mais ou menos aparentes (Georges; Vidal, 2012) a partir de políticas de estímulo ao empreendedorismo popular sob o manto da qualificação profissional e pessoal, de empreendedorismo de si (Silva, 2002) e de “empreendedorismo social". ${ }^{17}$ Nessas "zonas cinzentas"18 entre formalização e informalidade, direito e negócio, movimento social e empresariamento, tais políticas (assistência social, saúde, trabalho e renda, programas de incentivo às artes e à cultura, assim como relativas ao microempreendedorismo e economia solidária, construção em mutirão e, mais recentemente o MCMV Entidades), de um modo geral, apresentariam uma face de comprometimento e participação, enfatizariam o ideário partipacionista e autogestionário. Mas, de fato, poderiam ser identificadas, pelo menos no âmbito discursivo, como "políticas de ativação", ${ }^{19}$ como expedientes de natureza, em alguma medida, individualizante, conforme a retórica e o horizonte neoliberal (Hibou, 2011; Dardot; Laval, 2013). Assim, modulam-se as dimensões e os significados da pobreza e do enigma brasileiro com algumas das passagens que conduzem do indolente à massa marginal, dessa marginalidade à condição de trabalhador, mesmo que na informalidade, do trabalhador

${ }^{17} \mathrm{E}$ talvez aqui seja necessário perceber as iniciativas e empreendimentos habitacionais dos movimentos e associações populares sob o signo de práticas e discursos relativos 2 às dimensões desse mesmo "empreendedorismo" social.

${ }^{18}$ A noção é utilizada por Telles e Cabanes, bem como por

Azaïs, mas está ancorada, ao que tudo parece indicar, em

- Agamben, G. Homo Sacer - O poder Soberano e a Vida

N Nua. Belo Horizonte: Ed. UFMG, 2002 e Estado de Exce-

ção. São Paulo: Boitempo, 2004. Ver, a esse respeito, Telles,

V. e Cabanes, R. (org.) Nas Tramas da Cidade - trajetórias urbanas e seus territórios. São Paulo: Humanitas, 2006.

${ }^{19}$ Desde as iniciativas de organizações internacionais, tais o Banco Mundial, o Banco Interamericano de Desenvolvimento (BID), é possível identificar como políticas de ativacão aquelas que exigem ação individual em contrapartida aos benefícios alcançados, na contramão de sua concepção como direitos. A idéia está ancorada em especial em Rizek, C. e Georges, I - Emergência e Reinvenção: Novas e velhas políticas sociais no Brasil, anteriormente citado. informal ao excluído e da "exclusão" (de certo modo fetichizada) à condição de apartação social, do beneficiário de programas e políticas ao microempreendedor capacitado. Mas as relações entre as palavras e as coisas, os modos de enunciação e de designação acabam por se configurar como um segundo enigma que se repõe e se redesenha no horizonte das ciências sociais no Brasil.

Nos anos 2000, a polarização das políticas sociais e a criação crescente de um fosso entre um horizonte de acesso aos direitos de tipo universalista e de possibilidades efetivas de inserção social e profissional (por meio de políticas de acesso à saúde, assistência, moradia ou trabalho e renda), ou seja, a emergência de um potencial de conflito e de luta por direitos encontraria desdobramentos na concretização das políticas e programas habitacionais. Em suas formas "autogestionárias”, ainda que residuais em termos quantitativos, confere-se importância e peso às entidades de intermediação, de cunho político, comunitário, privado, religioso, articuladas ou não com a história dos movimentos populares e com os movimentos de luta por moradia em particular. Essa articulação parece ser um dos eixos mais interessantes das considerações relativas ao programa MCMV em sua modalidade Entidades.

\section{QUANTIDADES EM CAIXAS PRE- TAS: o programa Minha Casa Minha Vida - "entidades" em números}

A modalidade "Entidades" foi, ao que tudo indica, no contexto do programa MCMV, "conquistada" pelos movimentos, por interações e articulação nacional com o governo federal, presença institucional nos conselhos participativos ou interlocução permanente entre lideranças e técnicos do Ministério das Cidades e da Caixa Econômica Federal. O discurso sobre a inserção de movimentos e entidades populares no programa afirma, frequentemente, que “não tinham opção” se quisessem “participar da 
festa", atender a suas bases e realizar uma produção de outra natureza, que se diferenciasse qualitativamente da produção convencional. ${ }^{20}$

\section{MCMV "Entidades" e os movimen- tos por moradia: da "produção da demanda" ao monopólio de organi- zação?}

A produção do "Entidades" se localiza na chamada faixa 1 do programa (atende a famílias com renda de até $\mathrm{R} \$ 1.600,00$ ) e se submete praticamente às mesmas regras da produção empreendida pelas construtoras, com algumas especificidades. Herdeiro do programa Crédito Solidário, operando o mesmo fundo (FDS - Fundo de Desenvolvimento Social), agora alimentado com recursos orçamentários da União, a modalidade se diferencia no contexto geral do MCMV por confiar à Entidade Organizadora a responsabilidade pelo contrato, pela seleção, organização e indicação dos beneficiários - os quais devem se enquadrar nas regras gerais do programa, o que inclui a inscrição e a submissão aos critérios do CadÚnico. O "Entidades" também se diferencia pela possibilidade de se estabelecer um contrato preliminar, específico para a compra do terreno e pagamento antecipado dos projetos. Essa foi uma "vantagem competitiva" dada às associações nas disputas por terra em um mercado bastante aquecido pelo próprio MCMV, permitindo que os proprietários recebessem os valores relativos ao terreno tão logo se comprovasse junto à Caixa a viabilidade técnica e financeira do empreendimento. Com o terreno "na mão", inicia-se uma nova (e longa) jornada que envolve licenciamentos nos órgãos públi-

${ }^{20} \mathrm{Na}$ sede de uma das entidades que promovem um dos empreendimentos que escolhemos para acompanhar por meio de nossas incursões etnográficas, encontramos, no mural, as fotos orgulhosas da liderança ao lado de Lula, outra ao lado da então prefeita Luisa Erundina e outra ainda ao lado da também então prefeita Marta Suplicy. O jogo político que confere legitimidade a essa mesma lideranç permite mesmo que se alterem os locais de inserção dos grupos de futuros moradores no Cadastro único - negociação que foi garantida "por cima”, isto é, no âmbito das negociações com o Ministério das Cidades. cos, desenvolvimento dos projetos executivos (implantação, redes de infraestrutura interna, arquitetura, estrutura e fundações, instalações), orçamentos e suas aprovações. São processos que levam, no mínimo, um ano e meio e podem chegar a quatro anos facilmente. ${ }^{21}$ Só então se contrata a obra propriamente dita, a qual pode ser executada em regime de administração direta - em que compras e contratações de materiais e serviços são feitas diretamente pela entidade com a supervisão de uma assessoria ou de técnicos responsáveis pelas obras - ou por empreitada global - processo em que a entidade contrata uma construtora para executar a obra integralmente. Nos processos executados, as dimensões de administração adquirem outra especificidade, ou "vantagem competitiva", que leva em conta a natureza sem fins lucrativos das associações e a consequente inexistência do capital de giro: a execução das obras ocorre com a antecipação de até duas parcelas dos recursos, dando boas condições de negociação nas compras e contratações pelas entidades.

O programa "Entidades" tem, portanto, os requisitos que caracterizam a produção habitacional autogestionária à brasileira (ou o discurso sobre essa produção): permite que os futuros beneficiários, potencialmente selecionados e conhecidos antes dos processos de obra, participem dos projetos e das obras, conheçam os terrenos e seus entornos, opinem na concepção, acompanhem o modo como os recursos são empregados na execução das obras, apropriem-se dos excedentes que resultam de bons processos de compra e contratações e os reinvistam na melhoria da qualidade das moradias. Esses processos, tão ricos quanto complexos, poderiam representar uma cunha no contexto geral do MCMV.

Mas não é exatamente o que temos visto como resultado da pesquisa. Nessa espécie de gincana ou corrida de obstáculos, a dimensão

${ }^{21}$ Um dos empreendimentos que estamos acompanhando mais de perto se iniciou dentro do Programa Crédito Solidário há aproximadamente sete anos, conforme depoimento coletado por uma futura moradora. 
urbana desses conjuntos torna-se, aos olhos das entidades promotoras e dos "beneficiários", quase secundária. Praticamente a totalidade dos empreendimentos contratados no estado de São Paulo está sendo viabilizada em terrenos comprados no mercado, localizados em bairros periféricos precariamente consolidados, ou nas franjas da mancha urbana metropolitana. Reproduzem, de modo não raro agravado, a má localização dos empreendimentos, produzida pelas outras modalidades, numa integração precaríssima daqueles que Rolnik chamou de "os sem cidade". Com o valor do terreno embutido no valor da unidade, vale a velha lógica do terreno mais barato, com dimensões que tornem o empreendimento economicamente viável também pela quantidade de unidades a serem produzidas. Terrenos de menor porte e bem localizados, com acesso a equipamentos, serviços urbanos e comércio que atendam, não apenas à demanda existente, mas comportem o aumento da população do bairro decorrente da implantação dos conjuntos, não cabem no programa. ${ }^{22}$

É esse o contexto que açambarca, inclusive, a ação de movimentos historicamente vinculados à luta por moradia no centro que, desde os fins dos anos de 1990, promoveram uma série de ocupações em edifícios vazios nessas localizações, configurando uma tentaণ tiva de lá promover moradia popular. Como Фं já flagrara Maia (2012), em pesquisa de cunho 这 etnográfico, em edifícios ocupados no centro o paulistano, a conquista da moradia definitiva 更

à Cidade Tiradentes, que continuava a ser o ลิ

$\check{>} 22$ Durante o processo de pesquisa, pelo acompanhamen-

i to das atividades dos grupos e pelas entrevistas com sei

informantes, foi possível constatar que apenas um dele

conhecia a área e o terreno onde seria (será) construído

o conjunto. A grande maioria nunca esteve na área e não conhece suas condições de acesso, sua localização ou a

quantidade e qualidade dos equipamentos próximos à sua "futura" moradia. Também é significativo que as associações locais - algumas bastante conhecidas e enraizadas na vida associativa do pedaço do bairro - não têm nenhum conhecimento do destino da área reservada e comprada para a construção do conjunto. destino das famílias submetidas a remoções e reintegrações de posse dos imóveis das áreas centrais. Movimentos como o Fórum de Cortiços e o MMC (que mudou o significado do "C" de sua sigla de Centro para Cidade), por exemplo, estão viabilizando empreendimentos nos bairros periféricos do Lajeado, Guaianases e Cidade Tiradentes, depois de anos de luta em torno das possibilidades de produção habitacional no centro. As dimensões dos terrenos "viáveis" - pelo alto potencial construtivo, pela quantidade de unidades a serem construídas têm levado a uma prática de "consórcios" de movimentos e associações, situação que Maia (2012) também já tinha notado nas ocupações que eram compartilhadas por diversas siglas de movimentos e suas bases. Entidades habilitadas junto ao Ministério das Cidades, muitas vezes com trajetórias e filiações políticas distintas, têm estabelecido parcerias, compondo e constituindo "demandas", ${ }^{23}$ indicando famílias de suas bases, para que se viabilizem conjuntos que chegam à marca de mil unidades habitacionais, dividindo o empreendimento em diversos contratos para que sejam respeitados os limites de 300 unidades da normativa que regulamenta o programa.

Essas práticas configurariam uma guinada e (ou) uma nova caracterização para os movimentos de moradia? Em outros termos, quais as redefinições desses campos de força que tangenciam a questão das lutas pela moradia, as conformações e espacializações da pobreza e da precariedade, os movimentos e as formas de associativismo e suas reconversões? Como pensar ainda a reconversão de entidades que passaram a se constituir como "máquinas de produção" (na verdade, de "contratação") de unidades habitacionais? O MCMV Entidades constitui-se, enfim, como um enorme campo de consenso fora do qual não é possível vislumbrar nenhuma saída, nenhuma outra possibilidade de con-

23 "A produção da demanda", como prática de legitimação ou justificação de entidades de intermediação ou operadores de programas e serviços, é uma forma de governo vigente igualmente no setor da assistência, como foi mostrado por Georges e Santos, 2013. 
quista organizada da moradia. Não é por acaso, portanto, que as ações do MTST em São Paulo, que envolveram milhares de famílias em duas grandes ocupações de terra - a Nova Palestina, no extremo Sul, e a Copa do Povo, nos arredores do estádio do Itaquerão - desembocam em negociações em torno do MCMV. ${ }^{24}$

\section{A Via Crucis das entidades}

Habilitar-se junto ao Ministério das Cidades, pesquisar terrenos, negociar com proprietários, realizar ocupações e ações diretas, negociações com prefeituras; organizar, selecionar e cadastrar possíveis beneficiários; realizar estudos de viabilidade, licenciamentos, orçamentos; gerir os processos produtivos no canteiro [...] São eventos-chave de uma verdadeira via crucis que revelam uma sequência de entraves que ajudam a justificar uma produção que é ínfima e muito inferior às metas estabelecidas, a despeito das imprecisões e da baixa credibilidade dos dados oficiais, obtidos de fontes diversas. Nacionalmente, o "Entidades" representa $0,25 \%$ dos recursos investidos e $0,83 \%$ das unidades habitacionais contratadas no programa MCMV como um todo. Mais que isso, mostra-se menos efetiva que as demais modalidades, pois apenas $0,36 \%$ de todas as moradias concluídas e 0,18\% das entregues, com todas as legalizações exigidas no programa, foram produzidos pela modalidade.

Havia, no estado de São Paulo, até novembro de 2013, 39 contratos, que, analisados mais cuidadosamente, eliminando as duplicidades contidas nas bases de dados, representadas pelos contratos de "Compra Antecipada" e as divisões dos conjuntos entre entidades consorciadas, representam 3 empreendimentos. Desses, apenas 1 empreendimento é considerado entregue; outros 3 estão com as obras concluídas, somando 4 conjuntos habitados (apenas 2 na Região Metropolitana de São

${ }^{24}$ Cf. André Dal Bó e Cibele Rizek. O MTST: origens e lutas. São Paulo, mimeo, 2014.
Paulo); 6 estão com obras contratadas; 6 com obras iniciadas e 7 estão apenas com os terrenos comprados, enfrentando os árduos processos de licenciamento e desenvolvimento de projetos e orçamentos. Desse modo, a pesquisa qualitativa, as incursões etnográficas e as visitas aos empreendimentos permitiram um fértil diálogo entre quantidades e qualidades, o que, por sua vez, possibilita uma apreensão transversal e um trabalho de dentro e de perto que permite clarear o que significam os números das planilhas oficiais.

Para além dos dados e informações, o Programa MCMV em sua modalidade Entidades permite mais um conjunto de indagações sobre a natureza das relações que conformam e emolduram as novas e velhas formas da sociabilidade política brasileira a partir de uma articulação complexa de programas sociais. ${ }^{25}$ Se essa indagação ganhasse corpo, ela acabaria por exigir também novas lentes, novos prismas, que permitam qualificar o capitalismo brasileiro em sua face financeirizada, conformando, de maneira até certo ponto inédita, as relações de classe, as modulações das formas de sociabilidade política e das relações de poder. Haveria, assim, uma nova conformação dos modos de dominação e de construção (mais ou menos frustrada ou bem sucedida) de hegemonia e consenso nos quais os programas e políticas sociais de transferência de renda e de moradia - recobertos pela aura do protagonismo, da autogestão, dos empreendedorismos sociais, da participação da "sociedade civil" - ocupariam um lugar central. Dentro desses rearranjos e reconfigurações, tampouco seria possível qualificar as classes populares como protagonistas clássicas desse novo "patamar de desenvolvimento", marcado, assim, por truncamentos que operam entre e nas situações e dimensões estruturantes das posi-

${ }^{25}$ Cabe mencionar, como se verá adiante, que os projetos e empreendimentos do Programa MCMV Entidades exigem a inclusão dos futuros moradores no Cadastro Unico de assistência, configurando necessariamente uma demanda assistência, configurando necessariamente uma demanda
de baixa renda para os empreendimentos. A inscrição no Cadastro Único é parte da “via crucis" de construção da possibilidade de efetivação dos empreendimentos. 
ções de classe, assim como em suas formas de atuação e expressão cultural e política. Seria, então, possível perguntar quais são as relações entre esses truncamentos, obstruções e o chamado lulismo, por suas determinações, bem como pelos seus campos de conflito e relações de força, por suas ambiguidades e coalizões.

Ao buscar um exame da ponta mais frágil do programa MCMV - a modalidade Entidades -, algumas dimensões sociopolíticas acabaram despontando como questões possivelmente estruturantes do problema de pesquisa que aqui se desdobra. Ele diz respeito a uma pergunta sobre a face da pobreza no Brasil urbano, sobre suas eventuais especificidades contemporâneas, sobre a impossibilidade de caracterizar o momento presente como avanço ou retrocesso, exigindo, de fato, que se enfrente sua nova conformação, o que acaba por demandar, de um lado, procedimentos descritivos que permitam apreender tanto o desenho e a proposição do programa e suas transformações como sua ponta final na produção e reprodução do espaço e da vida da cidade.

Flagrar continuidades e pontos de inflexão talvez também seja tarefa que exija um esforço teórico de percepção dos processos de financeirização e seus sentidos em seus vínculos com a produção do espaço, seus desdobraposições, que talvez coloquem no horizonte, ao lado da necessidade de pensar o presente, um esforço de construção de novas categorias, de atualização de nomeações, de apreensão de deslizamentos que permitam afinal perguntar: que cidade é essa? Como vêm se reconfigurando a pobreza e a desigualdade urbanas e que $\dot{*}$ tensões, torções e conflitos vêm ganhando ลे densidade? Que Brasil urbano emerge desse conjunto múltiplo de processos? Que diagramas permitem descrever e pensar as novas configurações que combinam cidade, pobreza, programas e políticas públicas, seus operadores, programas de produção de moradia, movimentos sociais e suas mutações, em particular no âmbito da cidade de São Paulo?

\section{CONSIDERAÇÕES FINAIS: direitos, negócios e gestão}

Ainda sem necessariamente sistematizar as informações provenientes da pesquisa etnográfica nos dois empreendimentos selecionados, mesmo que essa constelação de informações seja inevitavelmente subjacente, as informações e a reflexão que compõem esse texto permitem apontar algumas conclusões e problematizações que cruzam a política habitacional com as políticas sociais do Brasil lulista.

A primeira diz respeito ao modo pelo qual o programa acaba por se constituir, com despolitização da questão da moradia e, sobretudo, do acesso à cidade. A "construção da demanda" dos grupos de candidatos a beneficiários dos empreendimentos se dá, sobretudo, por meio de relações de âmbito privado - relações de parentesco ou amizade, oriundas de relações pessoais - e é raro, entre os grupos pesquisados, encontrar alguém com nítida trajetória de luta no movimento de moradia, com tempo de participação que exceda o tempo de formação do grupo para a assinatura do contrato. ${ }^{26}$ Ao serem perguntados como chegaram ao grupo e à entidade, nossos entrevistados, em sua maioria, responderam que foi por meio de um amigo, parente ou conhecido, que teria apontado o longo caminho para a aquisição da casa própria. São relações que, somadas à conversão de entidades à produção de moradia, acabamos por denominar "associativismo de ocasião". Nesse contexto, é, no mínimo, curioso perceber que, mesmo em São Paulo - sede dos quatro movimentos de articulação nacional $^{27}$ que têm assento no Conselho Nacional das Cidades, capacidade institucional para interferir nos rumos da política pela proximidade e interlocução com o governo federal, responsáveis diretos pelas formulações e

${ }^{26}$ Entre as entidades pesquisadas, há uma exceção, na qual os beneficiários tinham trajetória mais antiga, com participação frequente em atos, manifestações e ocupações.

${ }^{27}$ CONAM (Confederação Nacional de Associações de Moradores), CMP (Central de Movimentos Populares), MNLM (Movimento Nacional de Luta pela Moradia) e UNMP (União Nacional por Moradia Popular) 
reformulações do programa -, os empreendimentos, em mais da metade (12 entre os 23), tenham sido contratados por entidades que não possuem vínculo algum com os quatro grandes movimentos. Uma situação que pode ser lida pelo viés "republicano" do acesso de qualquer associação ao programa (com origens e práticas diversas na assistência social, educação popular, melhorias urbanas e regularização fundiária), desde que consiga superar os vários obstáculos. Mas esse elemento oferece novas pistas para uma despolitização do problema da moradia e das possibilidades que o programa, em sua modalidade "entidades", permite: a amplitude do escopo dessas mesmas associações e sua vinculação e (ou) desvinculação possível com a longa e difícil trajetória de luta urbana e habitacional nas cidades brasileiras no âmbito das lutas pela reforma urbana e pelo "direito à cidade". ${ }^{28}$ Essas associações "externas" acabaram se convertendo à produção da moradia (não mais na perspectiva de melhorias, urbanização, regularização fundiária) a partir das oportunidades de "negócio", ou de uma espécie de nicho de mercado criado pelo programa, o que possibilita uma forte afinidade com os empreendedorismos, inclusive os de natureza social.

A obtenção da casa se configura como ponto de chegada de uma trajetória vista e vivida como pessoal - que resulta do esforço em permanecer e acreditar nas lideranças e grupos das associações. A conquista se reveste, assim, de um caráter moral que premia a persistência, a "confiança" nas lideranças e a "fé" de que "minha casa vai sair". A construção da demanda pelas entidades também passa por técnicas de produção de informações e por estratégias de cadastro que viabilizem o teto de renda, R\$ 1600,00 por mês, o que, em São Paulo, significa pouco mais de dois salários mínimos regionais. São essas estratégias que se somam a

${ }^{28}$ É interessante notar o deslizamento da bela noção de Lefebvre no âmbito de sua apropriação pelos movimentos que integraram a luta pela reforma urbana ou a luta pelo direito à moradia no Brasil. Essas apropriações, com sentidos diversos do original, acabaram por configurar a expressão "direito à cidade" como uma espécie de "categoria nativa”, com significados próprios ao longo das últimas décadas no Brasil. tantas outras, num processo de transformação dos movimentos, entidades e associações delas resultantes em "máquinas de produção de casas”, em operadores do programa e em intermediários entre a Caixa Econômica Federal e os agenciamentos do mercado imobiliário onde quer que ainda seja possível encontrar um terreno que satisfaça as exigências desenhadas no âmbito do PMCMV - Entidades. Essa operação é, frequentemente, uma poderosa armadilha, e toda sorte de "negócios" imobiliários acaba por compor uma frente que combina preços, acessos, contatos, em um contexto de forte valorização de terrenos nas regióes metropolitanas. Além de determinarem localizações distantes de equipamentos, infraestrutura e serviços urbanos considerados como elementos de uma "cidade plenamente constituída", nas bordas do tecido urbano, "de costas" para a cidade, as negociações imobiliárias para as quais o programa empurra as entidades resultam em procedimentos que estão nas dobras entre o lícito e o ilícito, entre as dimensões legais e ilegais praticadas nesse mesmo nicho do mercado imobiliário.

Esses elementos, em um campo de forças que guarda importantes afinidades com os processos de empresariamento social e associativo, permitem que se entreveja que a produção de moradia pelo programa tem um caráter paradigmático no que se refere à construção e à manutenção de pactos entre Estado, incorporadoras, grandes e pequenas construtoras, por um lado, e, com um investimento quase insignificante face ao conjunto da produção, os movimentos sociais por moradia, que conformaram uma trajetória de luta desde pelo menos os anos oitenta. Essa mesma produção - que, afinal, acontece onde é possível, isto é, nas piores localizações -, subsidiada por fundos públicos, acaba por reforçar, quando não agrava severamente, as linhas de segregação socioespacial. Casa de pobre para pobre, lugar de pobre para pobre. Mesmo quando foi possível perceber uma melhora importante na qualidade de projeto e de execução, isto é, quando houve intermediações importantes do 
movimento social organizado e de assessorias técnicas e políticas - experiências excepcionais e virtuosas, nos termos de Oliveira (2006) -, as formas de segregação determinadas pelas regras do mercado de terras se mostraram soberanas para não dizer incontornáveis. Talvez esse resultado seja o elemento sobre o qual seja preciso refletir, no cruzamento do universo dos direitos da casa e da cidade como direitos, e do que Lautier chamou "governo moral dos pobres", entre conquista e negócio, entre politização e tecnologias de acomodação e gestão da vida.

Recebido para publicação em 06 de Agosto de 2014 Aceito em 30 de setembro de 2014

\section{REFERÊNCIAS}

AGAMBEN, G. Homo Sacer. O poder soberano e a vida nua. Belo Horizonte: Ed. UFMG, 2002.

Estado de exceção. São Paulo: Boitempo, 2004.

AZAÏS, C. As zonas cinzentas no assalarimento: proposta de leitura do emprego e trabalho. In : AZAÏS, C.; KESSLER G.; TELLES, V. da Silva (orgs.). Ilegalismos, cidade política. Belo Horizonte: Fino Traço, 2012. p. 167-198.

BELLO, C. A. Governos Lula: consenso, coerção e hegemonia às avessas. São Paulo, mimeo, 2012.

BRAGA, R. A Política do precariado: do populismo à hegemonia lulista. São Paulo: Boitempo, 2012

CABANES, R. Cartas Filmadas Clichy sous Bois Guaianases: um projeto de Oficina de Vídeo. Proposta do coletivo ACLEFEU, Paris (mimeo), 2013.

ชิ

CEBALLOS, M. Le “détour du social” et les programmes de transferts monétaires conditionnés en Amérique latine: les cas de l'Argentine, du Brésil, du Chili et du Mexique. Tese de Doutoramento IEDES/Paris I, 2012.

के

DESTREMAU, B. GEORGES, I. Gouverner les pauvre $0^{\circ}$ en Amérique Latine: gérer les femmes par l'assistance. †ै Rapport de recherche final ANR Les Suds II - Latinassist i) septembre 2014.

管

? LAVAL, C.; DARDOT, P. La nueva razón del mundo.

2 Barcelona: Gedisa Editorial, 2013.

N

$\dot{8}$

(. Trabalho precário ou inclusão social a do saúde - dos agentes de proteção social da Região Metropolitana de São Paulo, Brasil. In: GEORGES, I.; LEITE, M. de Paula - (Orgs.). Novas configurações do trabalho e Economia solidária.São Paulo: Ed. Annablume, 2012. p. 77-106.

GEORGES, I.; SANTOS, Y. Garcia dos. A produção da "demanda": viés institucional e implicações políticas da - terceirização do trabalho social na periferia de São Paulo.

In: CUNHA, N. Vieira da; FELTRAN, G. de Santis. Sobre Periferias: Novos conflitos no espaço publico. Rio de Janeiro:Ed. Faperj/Lamparina, 2013. p. 159-177.

HIBOU, B. Anatomie politique de la domination. Paris: La Découverte, 2011.
IVO, Anete Brito Leal. Viver por um fio, pobreza e política social. São Paulo: Annablume, 2008.

LATINASSIS, Offre. Institutionnelle et logiques d'acteurs: femmes assistées dans six métropoles d'Amérique latine, projet de recherche ANR Les Suds II, 2010.

LAUTIER, B. La diversité des systèmes de protection sociale en Amérique latine: une proposition de méthode d'analyse des configurations de droits sociaux. Revue de la régulation, Capitalisme, institutions, pouvoirs, n. 11, Revue en ligne, 2012.

LEITE, M. de Paula. O trabalho no Brasil dos anos 2000: duas faces de um mesmo processo. In: VERAS de Oliveira, R.; GOMES, D. TARGINO, I (orgs.). Marchas e contramarchas da informalidade do trabalho. Das origens às novas abordagens. João Pessoa: UFPB, 2011. p. 29-63.

MAGALHAES, J. C. As entidades sociais e o surgimento de uma gestão concorrencial do engajamento cívico. In CABANES, R.; GEORGES, I.; RIZEK, C.; TELLES, V. (orgs.) Saídas de emergência, ganhar/perder a vida em São Paulo. São Paulo: Boitempo, 2011. p. 257-278.

MAIA PEREIRA, O. Lutas Urbanas por Moradia - O Centro de São Paulo. Tese de doutoramento, USP-IAU, São Carlos, 2012.

MARANHÃO, T. O sentido político das práticas de responsabilidade social empresarial no Brasil. In: CABANES, R.; GEORGES, I.; RIZEK, C.; TELLES, V. (orgs.) Saídas de emergência, ganhar/perder a vida em São Paulo. São Paulo: Boitempo, 2011. p. 237-256.

MARICATO, E. Impasse da política urbana no Brasil. Petrópolis: Vozes, 2011.

MINISTERIO DO DESENVOLVIMENTO SOCIAL E COMBATE A FOME. Brasil Sem Miséria. Data Social. http://aplicacoes.mds.gov.br/sagi/simulacao/layout/teste/ miv novo.php. Acessado em 9/11/2012.

OLIVEIRA, F. de Jeitinho e jeitão. Revista Piauí, out., 2012. OLIVEIRA, F. de, RIZEK, C. S. A era da indeterminação. São Paulo: Boitempo, 2007.

OLIVEIRA, F. de; BRAGA, R.; RIZEK, C. S. Hegemonia às avessas. São Paulo: Boitempo, 2010.

PAULANI, L. Brasil Delivery. São Paulo: Boitempo, 2008.

REGO, W. Leão e PINZANI, A. Vozes do bolsa família autonomia, dinheiro e cidadania. São Paulo: Editora Unesp, 2013.

RIZEK, C. S. Políticas sociais e políticas de cultura territórios e privatizações cruzadas. Revista Brasileira de Estudos Urbanos e Regionais, São Paulo, v. 15 n. 2, 2013.

RIZEK, C. S. Nomear e compreender a pobreza no Brasil contemporâneo. Rev. Brasileira Ciências Sociais, São Paulo, v. 24, n. 71, Out. 2009.

RIZEK, C. S., SANTOAMORE, C., CAMARGO, C. M. e outros. A inserção urbana através da produção do programa MCMV-Entidades: abordagem etnográfica de casos selecionados. Projeto de pesquisa aprovado pelo Ministério das Cidades/CNPq, São Paulo, mimeo, 2012.

RIZEK, C. S., GEORGES, I. Emergência e reinvenção: novas e velhas políticas sociais no Brasil, CENEDIC/IRD Projeto de cooperação bilateral, São Paulo, 2013, mimeo.

RODRIGUES, E., MINEIRO, E. Do Crédito Solidário ao MCMV Entidades: uma história em construção. In: LAGO, L. C. D. Autogestão habitacional no Brasil: utopias e contradições. Rio de Janeiro: Letra Capital: Observatório das Metrópoles, 2012.

ROLNIK, R., NAKANO, K. As armadilhas do pacote habitacional. Le Monde Diplomatique, mar. 2009.

SANFELICI, D. M. A metrópole no ritmo das finanças: 
implicações sócio-espaciais da expansão imobiliária no Brasil. Tese de Doutoramento, USP-FFLCH, 2013.

SANTOS, Y. Garcia dos. A gestão sexuada do social: os novos programas sociais na saúde e na assistência e reprodução das relações tradicionais de gênero. Relatório de pesquisa FAPESP/CEM. São Paulo, 2012.

SHMBO, Lúcia. Habitação social de mercado. A confluência entre Estado, empresas construtoras e capital financeiro. Belo Horizonte: Ed. C/Arte, 2012.

SILVA, Luis A. Machado da. Da informalidade a empregabilidade: reorganizando a dominacão no mundo do trabalho Caderno CRH, Salvado, Revista do Centro de Recursos Humanos da UFBA, n. 37, p. 81-109, jul/dez 2002
SINGER, A. Os Sentidos do Lulismo - Reforma Gradual e Pacto Conservador. São Paulo: Cia das Letras, 2011.

et al. Capitalismo e Modernização periférica no Brasil do Século XXI: desigual e combinado. USPCENEDIC, FFLCH, 2013. Mimeo.

TELLES, V. Silva da; CABANES, R. (orgs). Nas Tramas da Cidade - trajetórias urbanas e seus territórios. São Paulo: Humanitas/IRD, 2006.

ZIBECHI, R. Política y miséria. uma proposta de debate entre o modelo extractivo, los planes sociales y los goviernos progressistas. Buenos Aires: Editora Lavaca, 2011. 


\section{SOCIAL POLICIES, MANAGEMENT AND BUSINESS IN THE PRODUCTION OF CITIES: the program Minha Casa, Minha Vida - "Entities"}

\author{
Cibele Saliba Rizek \\ Caio Santo Amore \\ Camila Moreno de Camargo
}

\section{POLITIQUE SOCIALE, GESTION ET AFFAIRES DANS LA PRODUCTION DES VILLES: le programme ma maison, ma vie "entités"}

\author{
Cibele Saliba Rizek \\ Caio Santo Amore \\ Camila Moreno de Camargo
}

This text presents the results of a research about the program Minha Casa, Minha Vida - "Entities”, one of the social housing policies launched in 2009, as to its part in the group of social welfare programs of the governments of Lula and Dilma Rousseff. These results from a research which is still going on point to dilemmas, paradoxes, and dimensions which involve the demand, the operators, the production processes of the housing compounds, and the production and reproduction of inequality and segregation in the city of São Paulo. Also, it points to the constitution of a field of agreements which permeates the relations between movements for housing and the State inside what can be called Lulismo.

KeYwords: Housing policies. Housing movements. Social welfare. Outskirts.
Ce texte présente les résultats d'une recherche concernant le Programme Ma Maison Ma vie - "Entités", l'une des politiques du logement inaugurée en 2009 dans le cadre de la constellation de programmes sociaux des gouvernements de Lula et de Dilma Roussef. Les résultats de cette recherche, toujours en cours, indiquent des dilemmes, des paradoxes et des dimensions portant sur la demande, les opérateurs, les processus de production de l'ensemble des logements, la production et la reproduction des formes d'inégalités et de ségrégation socio-spatiale dans la ville de São Paulo ainsi que la création d'un champ de consensus qui imprègne les relations entre les mouvements pour le logement et l'État au sein de ce que l'on pourrait appeler le "lulisme".

Mots-CLEs: Politique du logement. Mouvements en faveur de l'habitation. Politiques sociales. Banlieues.

Cibele Saliba Rizek - Doutora em Sociologia. Professora do Programa de Pós Graduação em Arquitetura e Urbanismo do IAU/ Universidade de São Paulo. Pesquisadora do Centro de Estudos dos Direitos da Cidadania, também da Universidade de São Paulo. Tem experiência na área de Sociologia, com ênfase em Outras Sociologias Específicas, atuando principalmente nos seguintes temas: cidades, reestruturação produtiva, habitação, espaço público e cidadania. Publicações recentes: A coragem da crítica radical. Revista Em Pauta, v. 11, p. 215-218, 2013; Etnografias urbanas. ReDObRa, v. 12, p. 19-25, 2013; Uma Homenagem a Robert Castel. Revista Latinoamericana de Estudios del Trabajo, v. 18, p. 299-310, 2013; Políticas sociais e políticas de cultura: territórios e privatizações cruzadas. Revista Brasileira de Estudos Urbanos e Regionais, v. 15, p. 199, 2013.

Caio Santo Amore - Doutor em Planejamento Urbano (2013) pela mesma instituição. Desde 2005 atua como professor universitário, lecionando disciplinas de tecnologia aplicada, projeto arquitetônico e urbanismo e orientando Trabalhos Finais de Graduação (TFG). Em 2014 foi indicado em concurso para o cargo de Professor Doutor no Depto de Tecnologia da Arquitetura e do Urbanismo da FAUUSP. Desde 1998, atua como arquiteto na ONG de assessoria técnica Peabiru Trabalhos Comunitários e Ambientais, com cargo atual de coordenador geral. Tem experiência na área de Arquitetura e Urbanismo, com ênfase em ensino superior e em projetos de arquitetura, planos e estudos urbanísticos, coordenação de equipe, assessoria técnica a movimentos sociais e populares

Camila Moreno de Camargo - Arquiteta Urbanista pela Universidade Metodista de Piracicaba (2004), Mestre em Teoria e História de Arquietura e Urbanismo pela Universidade de São Paulo (2010), com pesquisa sob o título: Habitação Coletiva Popular na Área Central de Campinas: tendências e caracterização. Doutoranda junto ao Programa de Pós-Graduação do Instituto de Arquitetura e Urbanismo, Universidade de São Paulo, com pesquisa voltada para a produção habitacional autogestionária e a reestruturação das práticas de consumo contemporâneas no Brasil. Atua como docente do curso de Arquitetura e Urbanismo da Associação de Escolas Reunidas - Rio Claro, e profissionalmente enfocando temas como: Planejamento Urbano e Regional, Políticas Públicas de Habitação de Interesse Social e Mobilidade Urbana. 